\title{
Systematic Review: Research Trends in Underserved Students
}

\section{Vanitha Dewi Veeriah, Nurfaradilla bt Mohamad Nasri}

Faculty of Education, National Malaysia University, Bangi, Malaysia

Email:vanithaveeriah@gmail.com

How to cite this paper: Veeriah, V. D., \& Nasri, N. M. (2019). Systematic Review: Research Trends in Underserved Students. Creative Education, 10, 2922-2938. https://doi.org/10.4236/ce.2019.1012217

Received: October 21, 2019

Accepted: November 26, 2019

Published: November 29, 2019

Copyright (c) 2019 by author(s) and Scientific Research Publishing Inc. This work is licensed under the Creative Commons Attribution International License (CC BY 4.0).

http://creativecommons.org/licenses/by/4.0/ (c) (7) Open Access

\begin{abstract}
The issue of underserved students is something very common in the field of education and almost all countries have issues regarding underserved students in their own educational systems. A systematic review was conducted to find out trends in underserved students particularly in their achievement gap. In this study, issues regarding trends in underserved students and the factors that cause the achievement gap for underserved students were analyzed where 20 articles were selected using PRISMA protocol and Mc Dermott filtration methods. The findings are focused on the elements that cause underserved students such as the demography, school system, language, first generation which were identified as factors that create an achievement gap between underserved students and others. The study also focuses on the issues related to underserved students based on the reports by researchers from 2009 until 2019. Factors such as the policy makers, college management, ICT access and Prior Learning Assessment (PLA) are some of the ways which will help to bridge the achievement gap.
\end{abstract}

\section{Keywords}

Underserved Students, Achievement Gap, Demography, Inequality, School System, Academics, Education

\section{Introduction}

Underserved students are commonly known as under-resourced or underprepared students. In educational context, this group of students is always at the risk of failing (Zielezinski \& Hammond, 2016). It is because they do not receive sufficient resources and facilities in education like other normal students do. Therefore, the achievement gap between underserved students and normal students in education considered to be wide (U.S. Department of Education, 2016; 
Zielezinski \& Hammond, 2016). They are often recognized as a minority particularly of a race/ethnic, gender, first language, immigrant status, and age. They often have low-socioeconomic status, low performance in academics, under-credited or not on track to graduate (U.S. Department of Education, 2016; Zielezinski \& Hammond, 2016; Collions, 2011; Rendon, 2006). Some are considered as underserved students because of their poor school system (Zielezinski \& Hammond, 2016). Underserved students who are being referred in this study have one or more of these personal or social criteria which make them underserved. Underserved students often showcase a wide achievement gap compared to other students. This issue can be seen in all types of educational levels starting from the preschool until tertiary education.

\section{Research Objective and Purpose}

This study discusses about the issues of underserved students. The purpose of this study is to survey issues discussed regarding education trends in underserved students, especially, factors that create achievement gap for underserved students.

\section{Research Question}

The research questions, therefore are,

1) What are the issues regarding trends in underserved students?

2) What are the factors that create achievement gap for underserved students?

\section{Methodology}

Researchers used two steps in this study, first is Preferred Reporting Items for Systematic Review. Secondly, Meta-Analysis Protocols (PRISMA) protocol and the Mc Dermott model (2014) during the selection process of the review article.

\subsection{PRISMA Protocol}

Preferred Reporting Items for Systematic Review and Meta-Analysis Protocols (PRISMA) is a reference which helps researcher to plan and document review methods and findings (Moher, Shamseer, Clarke, Ghersi, Liberati, Petticrew, Shekelle, Stewart, \& PRISMA-P Group, 2015) PRISMA protocol consists of four steps. They are identification, screening, eligibility and included.

\subsubsection{Identification}

Researcher uses the ERIC, Sage and Google scholar databases at the identification stage through identification. Keywords such as underserved students, achievement gap, demography, inequality, school system, academics, and education have been used to search for relevant articles. Besides, researcher also created inclusive and exclusive criteria to get the data that exactly fits the objectives and purpose of this study. The criteria which have been included and excluded are as shown below: 
1) Use of the symbol "+", “-“, "and”, “or".

2) Limit the year of search, which is from 2009 to 2019.

3) Varies search sources such as journals, theses, proceedings, reviews, newspaper articles, blogs and reports.

4) Uses only articles which have both underserved students and achievement gap data.

\subsubsection{Screening}

About 16,600 articles related to underserved students were found in the first finding. Using certain criteria as shown below, these articles were then filtered again.

1) Focuses on achievement gap.

2) Ways to overcome achievement gap which faced by underserved students.

\subsubsection{Eligibility and Included}

A variety of data sources had been used in eligibility data collection. Therefore, researcher collected articles from journals, theses, proceedings, reviews, newspaper, blogs and reports. Only qualitative research articles were included and analysed using systematic review. The total articles got from the PRISMA protocol were roughly 572 . Figure 1 shows the process of selecting the relevant research articles to this study.

\subsection{Mc Dermott}

The process of filtering the articles continued by using Mc Dermott model. 572 articles which had been filtered using PRISMA protocol, were filtered again using Mc Dermott model to find out the actual quality of the selected articles. Mc Dermott model has been adapted for this study to see if those selected articles had the quality assessment criteria. There are six quality assessment criteria based on Mc Dermott model as shown in Table 1.

Articles had been graded based on the criteria fulfilled. Researcher graded the articles as A, B, C or D. Articles which achieved more than 6 criteria have been remained in the findings. However, articles which do not attain minimum three criteria were rejected. Thus, only 20 articles remained in researcher's findings. The article grading was made based on the table: Table 2 shows the descriptions for grading the article meanwhile Table 3 shows the quality of the articles based on the grading given my using the grading assessment.

\subsection{Coding}

Only 20 articles were selected from the filtration process based on the criteria that had been set. After the filtration process, these articles undergone coding process. Overall elements and issues that have been discussed in these 20 articles were coded as "E" (element) and "I" (issue). Numbering such as "1, 2, 3, ..." were also added to code "E" and "I" to quantify them (e.g.: E1, E1, I1, I2, ...). The reason researcher did code process on the 20 selected articles is to make easier and clearer for reference during the discussion about elements and issues. 


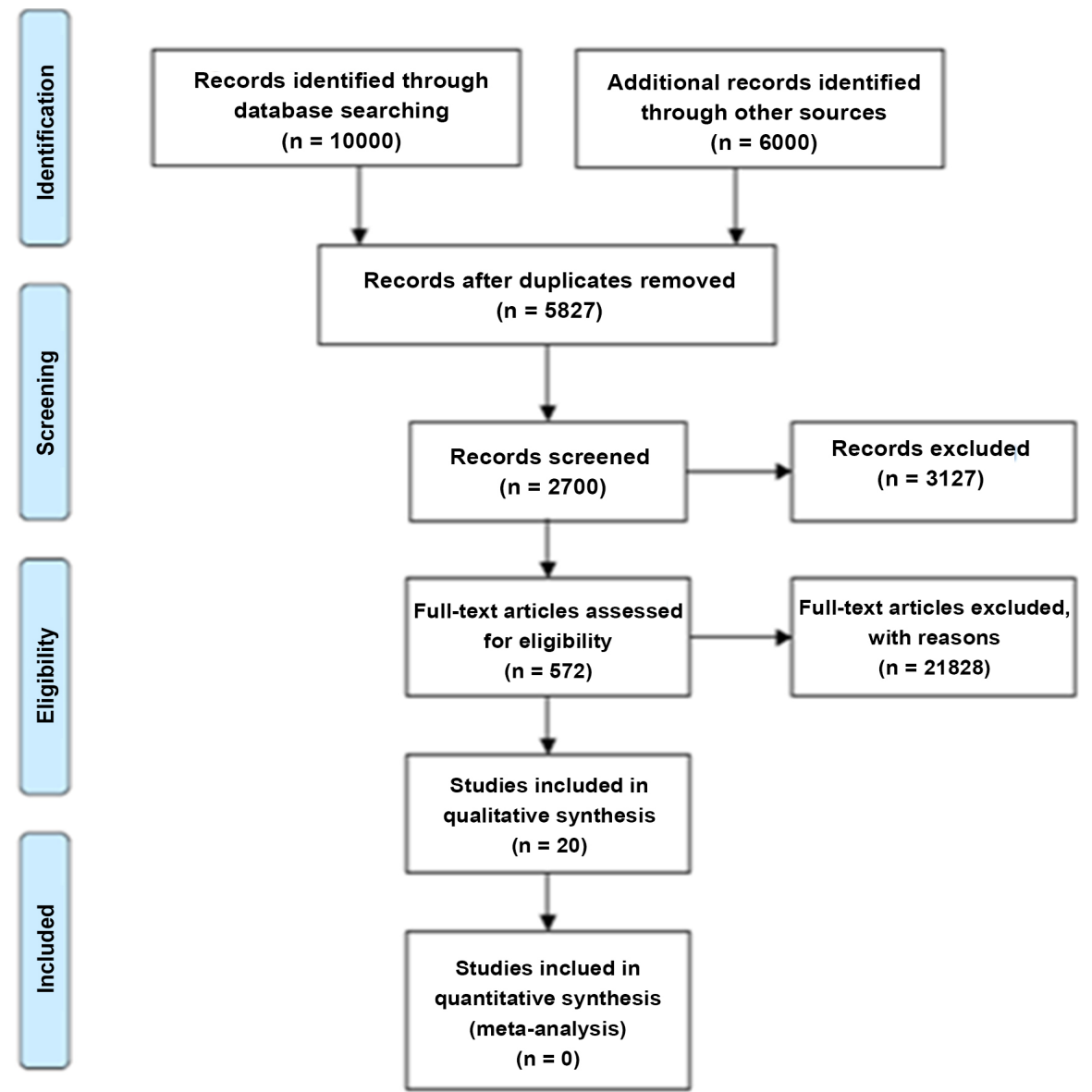

Figure 1. Data collection using PRISMA Protocol.

Table 1. Quality assessment of articles.

\begin{tabular}{ccl}
\hline No & Element & \multicolumn{1}{c}{ Descriptions } \\
\hline 1 & Goals and objectives & $\begin{array}{l}\text { Goals and objectives have been stated clearly. } \\
\text { Article explains clearly about planning, implementation } \\
\text { and development of the study. }\end{array}$ \\
3 & Study context & Article provides an adequate sample of research? \\
4 & Methodology & $\begin{array}{l}\text { Article provides a research methodology description } \\
\text { that includes frameworks for the study, data collection, } \\
\text { and data analysis. }\end{array}$ \\
5 & Data & $\begin{array}{l}\text { Data such as schedule, interview/focus and feedback } \\
\text { from observations have been included. Information is } \\
\text { being translated and analyzed clearly and precisely. }\end{array}$ \\
& The results of the study are & $\begin{array}{l}\text { Researcher verify the study's analysis by means of expert } \\
\text { review, feedback or other mechanisms. }\end{array}$ \\
\hline
\end{tabular}

\section{Findings}

There are many issues being discussed regarding underserved students in education world. In this study researcher only focused on elements, issues, year of publication and number of reported issues by researchers from these 20 articles 
Table 2. Description for grading of the article.

\begin{tabular}{cc}
\hline Grading of the article & Description \\
\hline A & Six criteria that have been stated clearly. \\
B & Five criteria that have been stated clearly. \\
C & Four criteria that have been stated clearly. \\
D & Three criteria that have been stated clearly. \\
\hline
\end{tabular}

Table 3. Quality assessment of the rated articles based on grading A, B, C and D.

\begin{tabular}{|c|c|c|c|c|c|c|c|c|}
\hline \multirow[b]{2}{*}{ Researcher } & \multirow[b]{2}{*}{ Year } & \multicolumn{6}{|c|}{ Criteria } & \multirow[b]{2}{*}{ Grade } \\
\hline & & Goals and objectives & Study context & Sample & Methodology & Data & $\begin{array}{l}\text { The results of the } \\
\text { study are validated }\end{array}$ & \\
\hline Berkowitz, Moore, Astor, \& Benbenishty & 2017 & l & l & I & I & I & I & A \\
\hline Borman, G. D., Grigg, J., \& Hanselman, P. & 2016 & l & l & I & I & l & l & A \\
\hline Gershenson, S. & 2013 & l & l & I & I & I & 1 & $\mathrm{~A}$ \\
\hline $\begin{array}{l}\text { Bakker, M., Torbeyns, J., Wijns, N., Ver- } \\
\text { schaffel, L., Smedt, B. D. }\end{array}$ & 2018 & l & I & I & I & l & I & A \\
\hline Quinn, D. M., \& Cooc, N. & 2015 & l & l & I & I & l & I & A \\
\hline Schroeder & 2009 & l & l & I & I & l & / & A \\
\hline Valentino & 2018 & I & I & I & I & l & I & $\mathrm{A}$ \\
\hline $\begin{array}{c}\text { Morgan, P. L., Farkas, G., Hillemeier, M. } \\
\text { M., \& Maczuga, S. }\end{array}$ & 2016 & 1 & I & l & I & l & / & $\mathrm{A}$ \\
\hline $\begin{array}{l}\text { Reardon, S. F., Kalogrides, D., Fahle, E. } \\
\text { M., Podolsky, A., \& Zarate, R. C. }\end{array}$ & 2018 & l & l & I & l & l & I & A \\
\hline $\begin{array}{c}\text { Adelson, J.L., Dickinson, E.R., \& } \\
\text { Cunningham, C. B. }\end{array}$ & 2016 & l & l & I & I & l & & B \\
\hline Holt, J. K., \& Duffy, D. Q. & 2017 & l & & I & I & l & I & B \\
\hline Jane \& Daniel & 2019 & l & & I & I & l & I & B \\
\hline Valant, J., \& Newark, D. A. & 2016 & l & I & & I & I & 1 & $\mathrm{~B}$ \\
\hline Finley, A., \& McNair, T. & 2013 & l & & I & I & l & & $\mathrm{C}$ \\
\hline Hart Research Associates & 2015 & l & & I & I & l & & $\mathrm{C}$ \\
\hline Chmielewski, A. K., \& Reardon, S. F. & 2016 & l & & I & I & l & & $\mathrm{C}$ \\
\hline $\begin{array}{l}\text { Quinn, D. M., Cooc, N., Mclntyre, J., \& } \\
\text { Gomez, C. J. }\end{array}$ & 2016 & l & & I & I & l & & $\mathrm{C}$ \\
\hline
\end{tabular}

since 2009 until 2019. The results were then analysed and presented the form of tables and graph for specific reference purpose. Table 4 shows the summary of the Include Empirical Articles which shows the issues, elements and findings obtained after reviewing the articles.

\subsection{Elements}

Researcher chose 4 common elements regarding underserved students' achievement gap in academics from the chosen 20 articles. Demography, school system, language, and first generation are the four common elements that was chosen to be discussed in this study. The details of the element are shown below in Table 5. 


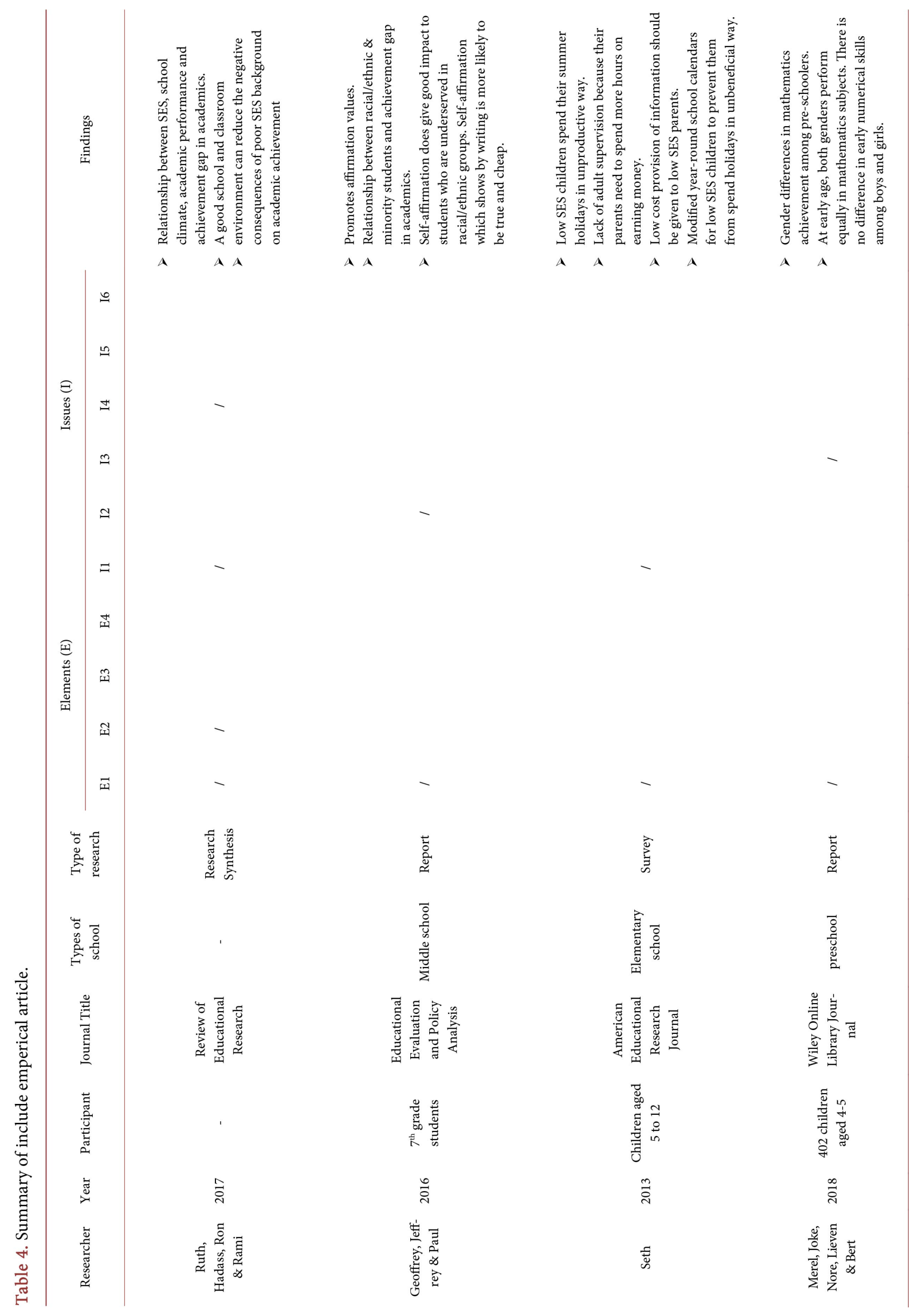




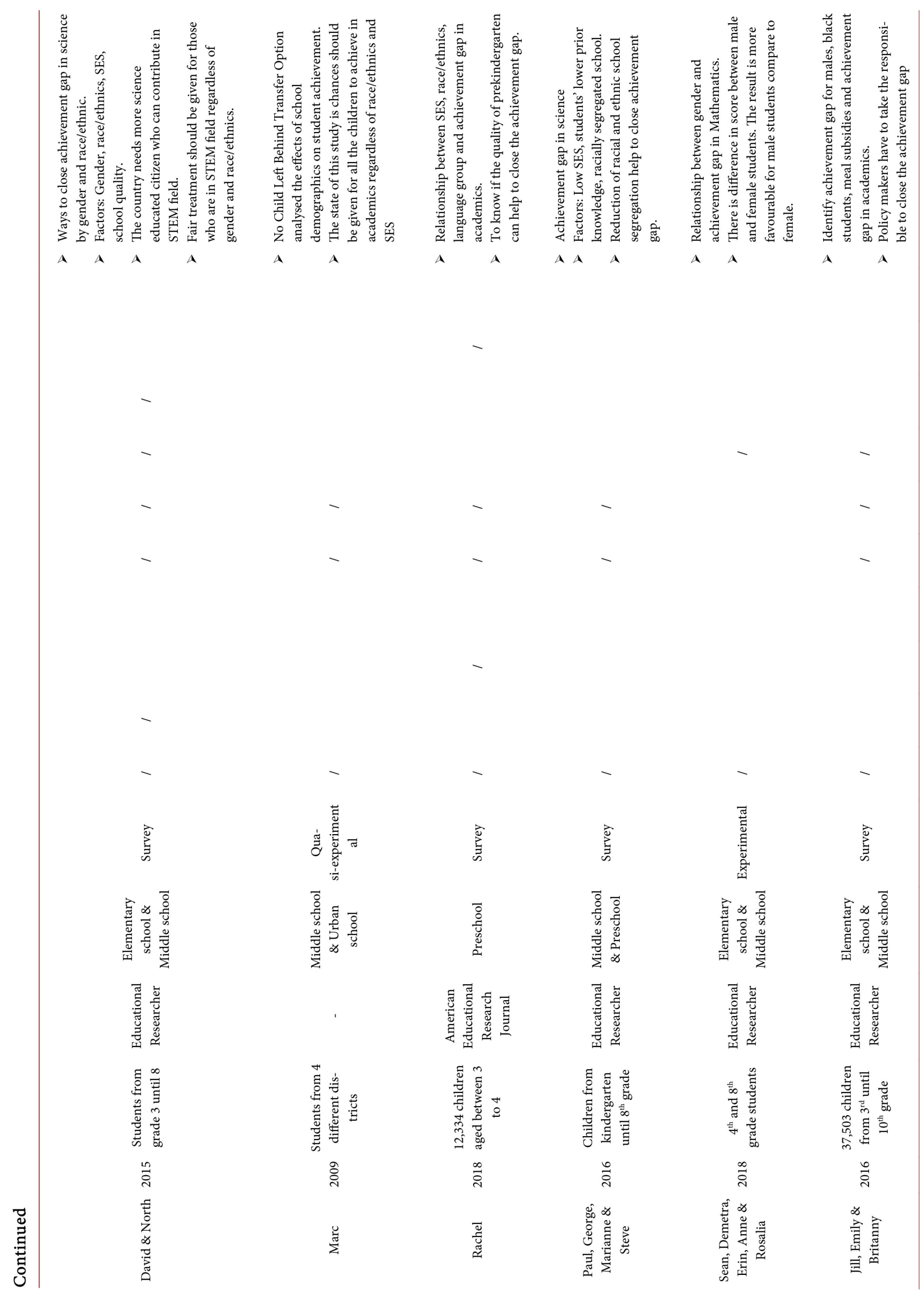




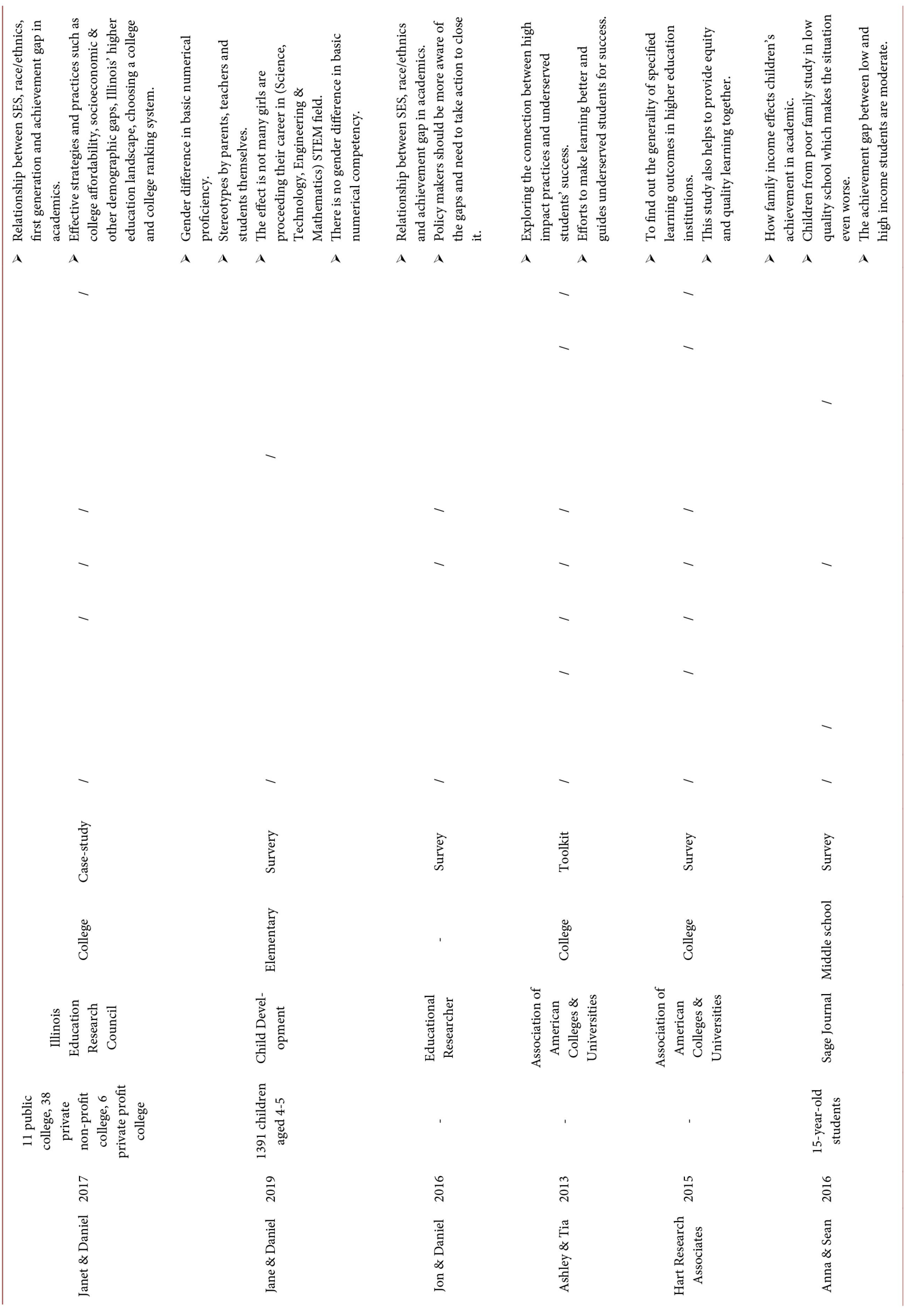




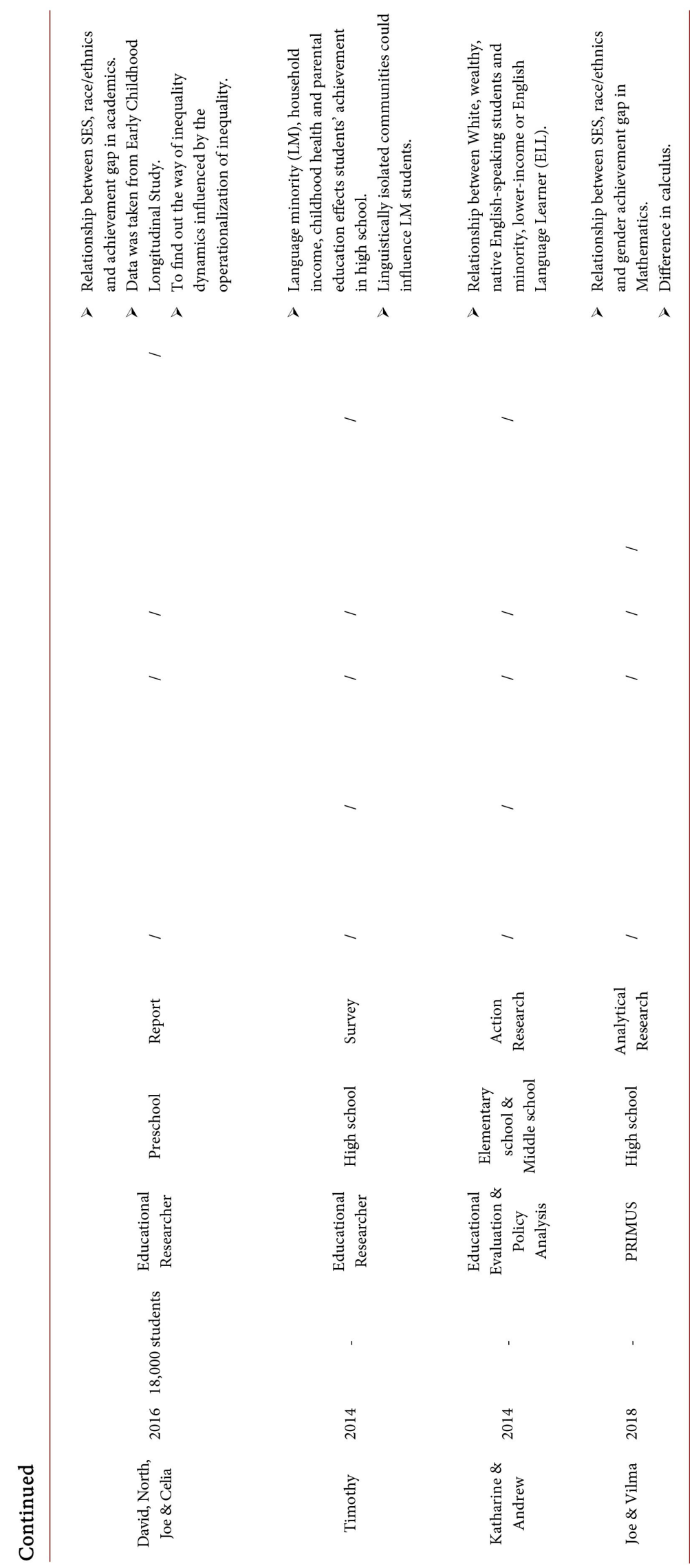


Table 5. Summary of include emperical article.

\begin{tabular}{ccc}
\hline Elements & Report number of articles & Percentage (\%) \\
\hline & SES: 16 & 33 \\
Demography & Race/Ethnic: 14 & 29.6 \\
& Gender:6 & 12.4 \\
School system & 3 & 6.5 \\
Language & 5 & 10.3 \\
First generation & 4 & 8.2 \\
\hline
\end{tabular}

In the demography element, SES had been reported in 16 articles which carries 33\%, race/ethnic had been reported in 14 articles which carries $29.6 \%$ and gender had been reported in 14 articles which carries $12.4 \%$. School system element had been discussed in 3 articles which carries 6.5\%. Language element had been reported in 14 articles which carries $10.3 \%$. Finally, first generation element had been reported in 14 articles which carries $8.2 \%$. Among all the elements, SES is the most reported element from the 20 articles. However, school system is the least reported element.

\subsection{Issues}

\subsubsection{Socioeconomic Status (SES)}

There is strong relationship between SES and achievement gap, where the lower the SES of a family, the bigger the achievement gap faced by the children in that family (Ruth, Hadass \& Rami, 2016; Quinn \& Cooc, 2015; Rachel, 2017; Adelson, Dickinson, \& Cunningham, 2016; Valant \& Newark, 2016; Chmielewski \& Reardon, 2016; Katharine \& Andrew, 2013; Champion \& Mesa, 2017; Salleh \& Ahmad, 2009). It is because a parent who has low SES cannot afford effective parenting strategies for their children (Ruth, Hadass \& Rami, 2016; Gershenson, 2013). This factor is also a barrier for students enter into tertiary education (Holt \& Duffy, 2017). Poverty affects the academic performances of the children in that family (Chmielewski \& Reardon, 2016; Salleh \& Ahmad, 2009). This factor also affects the learning duration of a child during summer holidays (Quinn, Cooc, Mclntyre, \& Gomez, 2016). Economically stable family could send their children to summer programme which is beneficial and help them to achieve higher in academic, whereas lower SES family cannot afford it (David et al, 2016).

\subsubsection{Race/Ethnics}

Race/ethnic difference among students creates a great achievement gap between them (Rachel, 2017; Adelson, Dickinson, \& Cunningham, 2016; Valant \& Newark, 2016; Katharine \& Andrew, 2013; Champion \& Mesa, 2017; Hamid \& Hanafiah, 2016; Hanafi, Ahmad, \& Ali, 2014). Race/ethnic disparities are a long existing problem for which the solution still cannot be found. The stigma where certain race/ethnic are higher than another is being seeded in humans' mind by 
the society or the organization where they belong to. As a consequence, the one that considered to be "lower" race/ethnic, specifically children, do not get their rights as a student in education field. This issue has resulted negatively for the underserved students who are said to be in 'lower' race/ethnic in teaching and learning process. This factor also makes it difficult for them to continue their studies in higher education (Holt \& Duffy, 2017).

\subsubsection{Gender}

There is no equal treatment between female students and male students in academics (Adelson, Dickinson, \& Cunningham, 2016). Gender norms and stereotypes are very common in academics (Reardon, Kalogrides, Fahle, Podolsky, \& Zarate, 2018). Gender inequality occurs when female students are not being served the same as the male students especially in STEM field. Male students are given more priorities when learning STEM subjects in school due to stigma where males are considered to be cleverer and smarter than the female students in STEM subjects. They get more encouragement from the teachers and parents compared to girls when they study STEM subjects. As the result, female students face lower job vacancies in this filed because the community does not believe that the female students are also able to achieve in STEM field as well (Bakker, Torbeyns, Wijns, Verschaffel, \& Smedt, 2018; Jane, Ian, \& Daniel, 2018).

\subsubsection{School System}

Some students are being referred as underserved students because of the poor school system (Zielezinski \& Hammond, 2016; Sani, 2014). Poor school system is referred to low school funding, underqualified teachers, low quality curriculum, inadequate book supply, insufficient teaching \& learning material, tools and poor teaching \& learning process (Salleh \& Ahmad, 2009; Marzuki, Mapjabi, \& Zainol, 2014). School system is a reason for the occurrence of achievement gap amongst students from different demographic factors (Ruth, Hadass, Rami, 2016; Quinn \& Cooc, 2015; Schroeder, 2009). A school with low quality and poor facilities could not afford to serve the students who study there for a better learning environment. Students from low quality school have lesser prior knowledge compared to their peers who studied in good quality school (Morgan, Farkas, Hillemeier, \& Maczuga, 2016).

\subsubsection{Language}

Language becomes a problem for underserved students when linguistic isolation occurs (Salleh \& Ahmad, 2009). Linguistic isolation means discriminating an individual whose mother tongue is not English or who does not speak English as their first language. These people are called language-minority (LM) students (Drake, 2014). Language becomes a barrier for children in learning process. Parents need to have better vocabulary in their non-native language they can help their children to perform better academically (Quinn \& Cooc, 2015). English Language Learners (ELL) are being discriminated because their first language is not English (Adelson, Dickinson, \& Cunningham, 2016; Katharine \& 
Andrew, 2013).

\subsubsection{First Generation}

First generation refers to children who are born to immigrant parents. They are called as the 'first generation' who born in that particular country. There are many obstacles faced by the first generation children, especially in academics (Finley \& McNair, 2013; Hart Research Associates, 2015; David et al., 2016). Lack of parental guidance makes first generation students perform poorly in academics. Parents who has permanent resident status spend more quality interaction with their children during summer break because they spend less hour in work compared to immigrant parents. Whereas, children from first generation family cannot spend more quality hours with their parents as they have to work over time or do more than one job to support the family. This ended up in first generation children spend more time viewing television during summer and this even widen the achievement gap in school (Gershenson, 2013).

\subsection{Year of Report}

Researcher has selected articles from year 2009 to 2019. Four elements and six issues which had been reported throughout this 11 years. The details are shown in Table 6:

Throughout this 11 years, demography is the only element that been reoccurring frequently for research trends in underserved students issue. It means the issues in demography element such as SES, race/ethnics and gender play a huge role in widening the achievement gap of underserved students. Those issues need to be paid more attention in order to prevent any worse situation for underserved students in academics.

\subsection{Researcher Reports}

48 issue had been reported from 20 articles relating underserved students. Table 7 shows the researcher and the number of reported issues.

Quinn \& Cooc (2015), Finley \& McNair, (2013), Hart Research Associates (2015) are the three collaboration reporters who integrated the most issues in one article. The number of issues which had been intergraded by them in a single article is four. Whereas, Borman, Grigg, \& Hanselman, (2016), Gershenson, (2013), Merel et al., (2016) talked only about one issue in an article.

\section{Discussion and Conclusion}

From this study, the elements and issues that create a wider achievement gap between underserved students and the normal students are revealed. Demographical element is the most popular one in this underserved students issue. In this modern era, the discrimination based on SES, race/ethnic and gender is still "being planted" within them and it cannot be changed easily. This stigma affects the underserved students by not letting them get academic opportunities which they supposed to get. Low SES students, children from the race or ethnic which 
considered to be "lower" and female students usually pay the price for this stigma (Berkowitz, Moore, Astor, \& Benbenishty, 2017; Quinn \& Cooc, 2015; Rachel, 2017; Adelson, Dickinson, \& Cunningham, 2016; Valant \& Newark, 2016; Chmielewski \& Reardon, 2016; Katharine \& Andrew, 2013; Champion \& Mesa, 2017).

Besides, poor school system also makes teaching and learning experience Table 6. Year of reported issuesbased on elements.

\begin{tabular}{|c|c|c|c|c|c|c|c|c|}
\hline \multirow{3}{*}{ Year } & \multicolumn{6}{|c|}{ Elements } & \multicolumn{2}{|c|}{ Total } \\
\hline & \multicolumn{3}{|c|}{ Demography } & \multirow{2}{*}{$\begin{array}{l}\text { School } \\
\text { System }\end{array}$} & \multirow{2}{*}{ Language } & \multirow{2}{*}{$\begin{array}{c}\text { First } \\
\text { Generation }\end{array}$} & \multirow{2}{*}{$(\mathrm{n})$} & \multirow{2}{*}{ (\%) } \\
\hline & SES & Race/Ethnic & Gender & & & & & \\
\hline 2009 & 1 & 1 & & & & & 2 & 4.1 \\
\hline \multicolumn{9}{|l|}{2010} \\
\hline \multicolumn{9}{|l|}{2011} \\
\hline \multicolumn{9}{|l|}{2012} \\
\hline 2013 & 2 & 1 & & & 1 & 1 & 5 & 10.4 \\
\hline 2014 & 2 & 2 & & & 2 & & 6 & 12.5 \\
\hline 2015 & 2 & 2 & 1 & 1 & 1 & 1 & 8 & 16.7 \\
\hline 2016 & 5 & 5 & 1 & 1 & & 1 & 13 & 27.1 \\
\hline 2017 & 2 & 1 & & 1 & & 1 & 5 & 10.4 \\
\hline 2018 & 2 & 2 & 3 & & 1 & & 8 & 16.7 \\
\hline 2019 & & & 1 & & & & 1 & 2.1 \\
\hline \multirow{2}{*}{ Total } & 16 & 14 & 6 & 3 & 5 & 4 & 48 & 100 \\
\hline & 33 & 29.6 & 12.4 & 6.5 & 10.3 & 8.2 & 100 & \\
\hline
\end{tabular}

Table 7. Number of reported issues based on researcher reports.

\begin{tabular}{cc}
\hline Researcher & Number of reported issues \\
\hline Ruth, Hadass, Ron \& Rami & 2 \\
Geoffrey, Jeffrey \& Paul & 1 \\
Seth & 1 \\
Merel, Joke, Nore, Lieven \& Bert & 1 \\
David \& North & 4 \\
Marc & 2 \\
Rachel & 3 \\
Paul, George, Marianne \& Steve & 2 \\
Sean, Demetra, Erin, Anne \& Rosalia & 1 \\
Jill, Emily \& Britanny & 3 \\
Janet \& Daniel & 3 \\
Jane \& Daniel & 1 \\
\hline
\end{tabular}


worst for the children who study there. Poor school system or management that is not paid any attention will make the students who study there be left out. The society or the community is also not able to help the school to get a better system because it needs many resources and it is not an overnight achievement to do so (Berkowitz, Moore, Astor, \& Benbenishty, 2017; Quinn \& Cooc, 2015; Schroeder, 2009). Language and first generation issues are often faced by the immigrants. They face difficulties during learning a language which is not their mother tongue. The proficiency of language, especially English affects their performances in academics although they can understand certain topics (Quinn \& Cooc, 2015; Adelson, Dickinson, \& Cunningham, 2016; Katharine \& Andrew, 2013).

There are a lot of ways to overcome issues faced by underserved students to bridge the achievement gap. Tertiary education institution needs to loosen up the criteria or be lenient to underserved students to help them graduate. For example, education fee can be reduced for underserved students as they normally come from lower SES family. This will encourage them to continue their higher studies (U.S. Department of Education, 2016; Rendon, 2006). Besides, colleges also can assess the students based on prior learning assessment (PLA). PLA is a special privilege given by college management to give "free" credit hours for underserved students. Attending extra curricular activities such as community service and volunteering after college hours are being calculated as credit hours for underserved students. Certain credit hours are being covered by PLA for them. This helps the underserved students who do not have enough money to continue their studies until the final semester. By applying this method, they also can graduate on time with their peers (Collions, 2011).

With the help of Information and Communication Technology (ICT) underserved students will be able to continue their higher education across international borders. Distance learning being common in Asia, a region where many developing countries are. It helps learners who stay in rural area to get equal opportunities in education as those from developed areas. Most of the distance learning includes online programmes which allows students to learn from their home. The lecturers also get paid extra to deliver quality teaching for online learners (Molly, 2016; Clothey, 2010).

Today's education environment more likely instils $21^{\text {st }}$ century learning skills in every learning individuals. One of the most popular learning skill is the 4C's which has collaboration and communication elements in it. It is a great opportunity for underserved students who are being online learners to improve both communication and collaboration skills through videoconferencing and virtual live lectures. The cost will also be minimal. Moreover, it is a great gateway for underserved students who get discriminated by their genders, for example in Saudi Arabia where female students are allowed to communicate and collaborate with male lecturers without being seen by them (Clothey, 2010).

Policy makers also need to come forward to do some changes in current policies to create more rational and liberal government. They have to be aware of the 
needs and priorities of underserved students to ensure no citizens are left behind in their country, especially in education fields. It's a responsibility of every policy makers to practice 'education is for all' perception in their respective countries (Gershenson, 2013; Ruth et al., 2016; Borman, Grigg, \& Hanselman, 2016; Paul et al., 2016; Quinn \& Cooc, 2015; Rachel, 2017; Adelson, Dickinson, \& Cunningham, 2016; Holt \& Duffy, 2017; Valant \& Newark, 2016; Reardon, et al., 2018; David, North, \& Celia 2016; Drake, 2014). The issues faced by underserved students are not something new. The future generation must be aware of this wrong notion against underserved students and keep working on to change the community norm, as it can provide a better future for the underserved students.

In future, this research can be continued by focusing demography elements alone. It is because demography factor alone gives such a strong impact on underserved students' achievement gap in academics. Moreover, researchers can be more focused on ways to overcome this global issue rather than talking about the factors deeply.

\section{Conflicts of Interest}

The authors declare no conflicts of interest regarding the publication of this paper.

\section{References}

Adelson, J. L., Dickinson, E. R., \& Cunningham, C. B. (2016). A Multigrade, Multiyear Statewide Examination of Reading Achievement: Examining Variability between Districts, Schools, and Students. Educational Researcher, 45, 258-262.

https://doi.org/10.3102/0013189X16649960

Bakker, M., Torbeyns, J., Wijns, N., Verschaffel, L., \& Smedt, B. D. (2018). Gender Equality in 4- to 5-Year Old Preschoolers' Early Numerical Competencies. Developmental Science, 22, e12718. https://doi.org/10.1111/desc.12718

Berkowitz, R., Moore, H., Astor, R. A., \& Benbenishty, R. (2017). A Research Synthesis of the Associations between Socioeconomic Background, Inequality, School Climate, and Academic Achievement. Review of Educational Research, 87, 425-469. https://doi.org/10.3102/0034654316669821

Borman, G. D., Grigg, J., \& Hanselman, P. (2016). An Effort to Close Achievement Gaps at Scale through Self-Affirmation. Educational Evaluation and Policy Analysis, 38, 21-42. https://doi.org/10.3102/0162373715581709

Champion, J., \& Mesa, V. (2017). Pathways to Calculus in U.S. High Schools. Primus, 28, 508-527. https://doi.org/10.1080/10511970.2017.1315473

Chmielewski, A. K., \& Reardon, S. F. (2016). Patterns of Cross-National Variation in the Association between Income and Academic Achievement. AERA Open, 2, 1-27. https://doi.org/10.1177/2332858416649593 http://ero.sagepub.com

Clothey, R. (2010). Current Trends in Higher Education: Expanding Access in Asia Pacific through Technology. Comparative \& International Higher Education, 2, 3-5. https://doi.org/10.5195/EHE.2011.29

Collions, R. K. (2011). Underserved Students Who Earn Credit through Prior Learning Assessment (PLA) Have Higher Degree Completion Rates and Shorter Time-to-Degree. 
http://www.cael.org/pdf/PLA Fueling-the-Race.pdf

Drake, T. A. (2014). The Effect of Community Linguistic Isolation on Language-Minority Student Achievement in High School. Educational Researcher, 43, 327-340. https://doi.org/10.3102/0013189X14547349

Finley, A., \& McNair, T. (2013). Assessing Underserved Students' Engagement in High Impact Practices. AC\&U Publications. http://www.aacu.org/assessinghips

Gershenson, S. (2013). Do Summer Time-Use Gaps Vary by Socioeconomic Status? American Educational Research Journal, 50, 1219-1248. https://doi.org/10.3102/0002831213502516

Hamid, Z., \& Hanafiah, M. G. (2016). Pemikiran belia Malaysia: Pengaruh umur, etnisiti dan status ekonomi. Malaysia Journal of Society and Space, 12, 92-102.

Hanafi, W. A. W., Ahmad, S., \& Ali, N. (2014). Faktor budaya dan persekitaran dalam prestasi pendidikan anak Orang Asli Malaysia: Kajian kes di Kelantan. Malaysian Journal of Society and Space, 10, 107-122.

Hart Research Associates (2015). Bringing Equity and Quality Learning Together: Institutional Priorities for Tracking and Advancing Underserved Students' Success.

Holt, J. K., \& Duffy, D. Q. (2017). Cornerstones of Student Success: Institutions Yielding High Return on Investment for Underserved Students. Edwardsville, IL: Illinois Education Research Council at Southern Illinois.

Jane, H. E., Ian, J. M., \& Daniel, A. (2019). More Similar than Different: Gender Differences in Children's Basic Numerical Skills Are the Exception Not the Rule. Child Development, 90, e66-e79. https://doi.org/10.1111/cdev.13044

Katharine, S. O., \& Andrew Mc E. (2014). More than Sanctions: Closing Achievement Gaps through California's Use of Intensive Technical Assistance. Educational Evaluation and Policy Analysis, 36, 281-306. https://doi.org/10.3102/0162373713510967

Marzuki, M., Mapjabi, J., \& Zainol, R. M. (2014). Mengupas keciciran pelajar Orang Asli Malaysia: Suatu tinjauan ke dalam isu aksesibiliti sekolah. Malaysian Journal of Society and Space, 10, 189-198.

Moher, D., Shamseer, L., Clarke, M., Ghersi, D., Liberati, A., Petticrew, M., Shekelle, P., Stewart, A. L., \& PRISMA-P Group (2015). Preferred Reporting Items for Systematic Review and Meta-Analysis Protocols (PRISMA-P) 2015 Statement. Systematic Reviews, 4, Article No. 1. https://doi.org/10.1186/2046-4053-4-1

Morgan, P. L., Farkas, G., Hillemeier, M. M., \& Maczuga, S. (2016). Science Achievement Gaps Begin Very Early, Persist, and Are Largely Explained by Modifiable Factors. Educational Researcher, 45, 18-35. https://doi.org/10.3102/0013189X16633182

Quinn, D. M., \& Cooc, N. (2015). Science Achievement Gaps by Gender and Race/Ethnicity in Elementary and Middle School: Trends and Predictors. Educational Researcher, 44, 336-346. https://doi.org/10.3102/0013189X15598539

Quinn, D. M., Cooc, N., Mclntyre, J., \& Gomez, C. J. (2016). Seasonal Dynamics of Academic Achievement Inequality by Socioeconomic Status and Race/Ethnicity: Updating and Extending Past Research with New National Data. Educational Researcher, 45, 443-453. https://doi.org/10.3102/0013189X16677965

Reardon, S. F., Kalogrides, D., Fahle, E. M., Podolsky, A., \& Zarate, R. C. (2018). The Relationship between Test Item Format and Gender Achievement Gaps on Math and ELA Tests in Fourth and Eighth Grades. Educational Researcher, 47, 284-294. https://doi.org/10.3102/0013189X18762105

Rendon, L. I. (2006). Reconceptualising Success for Underserved Students in Higher Education. 
Salleh, M. J. B., \& Ahmad, A. R. (2009). Kesedaran pendidikan dalam kalangan masyarakat Orang Asli (pp. 47-58). Bangi: Penerbit UKM. Hlm.

Sani, N. (2014). Narrowing the Literacy Gap of Indigenous Studens: What Are the Challenges? Jurnal Personalia Pelajar, 17, 19-30.

Schroeder, M. (2009). No Child Left behind Transfer Option: Impact on School Site Demographics and Student Achievement. Sarjana Dalam Pendidikan. University San Marcos.

U.S. Department of Education (2016). Advancing Diversity and Inclusion in Higher Education. Analysis, 36, 281-306.

Valant, J., \& Newark, D. A. (2016). The Politics of Achievement Gaps: U.S. Public Opinion on Race-Based and Wealth-Based Differences in Test Scores. Educational Researcher, 45, 331-346. https://doi.org/10.3102/0013189X16658447

Valentino, R. (2018). Will Public pre-k Really Close Achievement Gaps? Gaps in Pre-Kindergarten Quality between Students and across States. American Educational Research Journal, 55, 79-116. https://doi.org/10.3102/0002831217732000

Zielezinski, M. B., \& Hammond, L. D. (2016). Promising Practices: A Literature Review of Technology Use by Underserved Students.

https://www.researchgate.net/publication/304040744 